\title{
El tratamiento del VIH/sida en los periódicos españoles, investigar para propiciar nuevos relatos periodísticos
}

José Luis Terrón Blanco*

Resumen: Este texto pretende, por un lado, ofrecer los resultados de una investigación realizada entre los años 2005 y 2010 por el Observatorio de Comunicación y Salud (InCom-UAB) con el objetivo de conocer cómo tratan los diarios españoles las informaciones sobre el VIH/sida y, por otro, dar cuenta de las acciones emprendidas por Red 2002 para intentar influir en la agenda de los medios y en su confección de las informaciones con tal de evitar relatos periodísticos erróneos, parciales o estigmatizantes. La investigación se inscribe en el análisis de contenidos y tiene una finalidad de intervención social.

PPCC: VIH/sida, prensa, tratamiento, aplicación

\section{Introducción}

Este artículo pretende resumir las conclusiones a las que se llega en la investigación $E l$ tratamiento del VIH/sida en los medios de comunicación escritos españoles: $A B C, E l$ Mundo, El País, El Periódico y La Vanguardia, así como las acciones que ha emprendido el Observatorio de Derechos Humanos y VIH/sida de Red2002 ${ }^{1}$ a partir de los resultados de dicha investigación.

A finales del 2005, el ODH de Red2002 emprendió el proyecto Una nueva imagen para el VIH. Este proyecto surge de la percepción de que es necesario mejorar la manera en que se ofrece la información relacionada con el VIH/sida en los medios de comunicación en España, por lo que encarga al Observatorio de Comunicación y Salud (InComUAB) un estudio sobre el tratamiento del VIH/sida en los medios de comunicación escri-

\footnotetext{
* Observatorio de Comunicación y Salud (InCom-UAB) y Departament de Comunicació Audiovisual i Publicitat I de la UAB (joseluis.terron@uab.cat).

${ }^{1}$ Red comunitaria sobre el VIH/sida del Estado español (www.red2002.org.es); durante 2011 ha pasado a llamarse RedVIH.
} 
tos españoles con la finalidad de elaborar una guía de buenas prácticas dirigida a los periodistas encargados de redactar piezas sobre el VIH/sida y, de esta forma, contribuir a propiciar un cambio en la imagen que ofrecen los medios sobre el VIH/sida. Como veremos más adelante, este proyecto inicial varió sustancialmente, pero cabe adelantar que, entre otras cosas, se ha pasado de una única investigación inicial a otra en la que se vienen estudiando los mismos medios, con igual metodología e idénticos propósitos cada dos años. Por eso hablamos de distintas oleadas: la de 2006, la de 2008 y la de 2010.

Como objeto de estudio se escogieron cinco periódicos: ABC, El País, El Mundo, El Periódico y La Vanguardia. Se eligieron los diarios mencionados por ser los de más difusión en España. A su vez, tienen líneas editoriales bien diferenciadas, sus redacciones centrales están en dos ciudades diferentes (Madrid y Barcelona), los cinco periódicos cuentan con periodistas especializados en salud y todos ellos cuentan con suplementos o páginas específicas dedicadas a este tema. De estos diarios se analizan todas las informaciones que trataban el VIH-sida entre los meses de octubre y marzo (para así incluir el día 1 de diciembre y poder apreciar los flujos informativos).

Entre las oleadas se dejan transcurrir dos años para ver, por un lado, si se han producido variaciones en el tratamiento informativo y, por otro, para evaluar el alcance de las acciones emprendidas por Red2002.

La investigación, metodológicamente, se inscribe en el análisis de contenido y, en síntesis, pretende averiguar de qué se hablaba cuando supuestamente se escribe sobre VIH/sida, cuándo y cuánto se informa, de quiénes se habla, qué fuentes se utilizan (¿los miembros de la comunidad VIH/sida se utilizan como fuente?), cómo se informa haciendo un especial hincapié en la transmisión correcta o incorrecta de mensajes científicos), con qué carácter, qué características tienen esas informaciones (género, sección, edición, autoria, etc.), si estigmatizan y si se da un tratamiento de género.

Para poder acceder a todas las informaciones, fuera cual fuera la edición de los respectivos diarios, se utiliza la herramienta informática que ofrece Mynews ${ }^{2}$. De esta manera nos aseguramos el poder trabajar con todas las piezas que trataran el VIH/sida; sólo descartamos aquellas que se repetían en las distintas ediciones de un mismo diario. Hablamos de piezas y no de noticias para englobar a todas las informaciones, fueran cuales fueran sus géneros o sus registros lingüísticos, que también son objeto de estudio en esta investigación.

\section{Resultados de la investigación}

De manera sucinta presentaremos algunos de los datos más relevantes de estas tres oleadas ${ }^{3}$.

\footnotetext{
${ }^{2}$ www.mynews.es

${ }^{3}$ Se puede acceder a las investigaciones completas en la siguiente dirección: www.portalcomunicacio.com/ocs/esp/inv_det. asp?id_inves=8 . En las investigaciones han participado José Luis Terrón Blanco, Ramón García Sedó, Luisa del Carmen Martínez y María José Gorozpe.
} 


\subsection{Flujos informativos}

Mientras que en España el número de informaciones biomédicas aumenta (según el Informe Quiral $2009^{4}$ un $8,83 \%$ en 2008), las que se refieren al VIH/sida se estancan. En nuestro estudio se contabilizan 427 piezas (469 en la primera oleada y 435, en la segunda). Por otro lado, según Google Trends los flujos informativos, tanto globalmente como en España, tras la caída de 2007, aumenta en 2008 y se mantiene en 2009. Los expertos, y nosotros mismos, augurábamos que se daría un descenso considerable en el número de informaciones sobre el VIH/sida. No ha sido así.

Por ejemplo, en 2006 Fermín Apezteguías (PRSalud, 2006) advertía que "el sida ha desaparecido de los ojos de la gente y entonces hemos pensado que esta era una enfermedad superada y hemos dejado de preocuparnos por esta enfermedad y esto supone una nueva amenaza, porque el SIDA sigue ahí". Pocos años más tarde Lynette Lee Corporal (2009) escribe un artículo en el que se denuncia la escasa cobertura que suscitó el IX Congreso Internacional sobre Sida en Asia y el Pacífico, así como el poco espacio que se le dedica en general al VIH/sida en los medios asiáticos, a la par que pone de relieve como suele ser habitual un tratamiento sensacionalista.

¿A qué se debe este leve descenso? Consideramos que a varias causas:

- Uno de los criterios de noticiabilidad es la novedad; el VIH/sida no se percibe como noticia, tal como apunta Alejandro Brito (2007:13): “comunicadores e informadores ya no perciben al VIH/sida como noticia, "no estamos ante un tema novedoso", arguyen. Aparentemente, sobre esa epidemia ya se dijo todo lo que se tenía que decir".

- Sólo la construcción de relatos con nuevos enfoques ${ }^{6}$ y nuevos datos posibilita la permanencia en la agenda de los medios, dado que la noticia que esperan todas las redacciones es la consecución de una vacuna; de ahí que cualquier indicio en este sentido se torne en noticia destacada.

- Siguiendo a M. Nicolás y a M. Martín', el VIH/sida sería ya un 'postproblema' y sólo espasmódicamente (por ejemplo, esos indicios de consecución de una vacuna o la salida a luz pública de episodios de discriminación) vuelve a ganar espacio en la agenda de los medios.

- El acceso a los tratamientos médicos en Occidente le ha restado dramatismo (otro criterio de noticiabilidad), en tanto que sida ya no equivale a muerte. Como

\footnotetext{
${ }^{4}$ http://www.fundaciovilacasas.com/es/proyecto_salud/informe_Quiral?buscar=true\&anyo= 2009

${ }^{5}$ Fermín Apezteguía es periodista especializado en salud en El Correo de Bilbao, y autor del libro basado en egodocumentos sobre el VIH/sida Ahora que lo tengo.

6 "Los medios de comunicación cubren con demasiada frecuencia el VIH como un tema de salud, cuando es mucho más que un hecho médico, científico o sanitario" (Casabona, 2009). Léase también Mercado Martinez, FJ; Robles Silva, L; Moreno Leal, N; Franco Almazan; C (2001); estos autores se quejan de que en demasiadas ocasiones la prensa también reproduce el modelo biomédico de la enfermedad y no aborda temas importantes para determinados segmentos de la población, incluido el paciente.

${ }^{7}$ Martínez Nicolás, MA (1994): "La información periodística en la crisis del Sida. Algunos temas de interés para la investigación comunicativa”, Anàlisi: 16: 89-105.

${ }^{8}$ Martín Llaguno, M (2000): "De la detección al recuerdo: una historia periodística del SIDA", en Zer, 8: http://www.ehu. es/zer/zer8/8martin3.html
} 
nos advierte Casabona (2009), de la Fundació Sida i Societat, “curiosamente, el sida se ha alejado de los medios de comunicación, y el mensaje de que la epidemia sigue descendiendo gracias a los tratamientos es aún frecuente. Parece como si el éxito logrado con los ARV para convertir esta enfermedad en una infección crónica y procurar una buena calidad de vida a los afectados se haya extrapolado al propio curso de la epidemia. Pero, como indican los datos sobre VIH de las comunidades autónomas que los tienen, el número de nuevos diagnósticos se mantiene estable y en algunos subgrupos incluso ha aumentado".

- Y, por último, la falta de especialización en periodismo en salud, que, por ejemplo, impide en numerosos casos la inteligibilidad de las estadísticas epidemiológicas o el acceso a fuentes científicas o el contemplar nuevas corrientes científicas como la epidemiología política.

Por otro lado, las informaciones siguen concentrándose alrededor de los eventos ${ }^{9}$; esta concentración es aún mayor en el último periodo estudiado. Durante la semana de 1 de diciembre se insertaron 86 piezas, o sea un 20,14\% del total; en la oleada anterior sólo el $16 \%$ de las piezas. Una vez más se constata como la agenda se construye a partir del acontecimiento (Ampuero, 2006; Brito, 2007). Las otras fechas con mayor oferta informativa coinciden con las Conferencias Internacionales sobre el sida y en la última oleada el mundial de fútbol de Sudáfrica ${ }^{10}$.

De nuestras investigaciones se desprende que mientras que en 2006 el 60,55\% de las piezas que hablaban sobre el VIH/Sida tenían como argumento central al propio VIH/ sida, en 2008 tan sólo ocurría en el 49, $20 \%$ en 2010 en un 49,9\%; o sea, se habla menos del VIH/sida y en la mayoría de los casos para hablar de otros temas (por ejemplo, en la última oleada aumenta la presencia de personajes mediáticos en 'actos solidarios'). El VIH/sida aparece con frecuencia como argumento para intensificar lo doloso de una situación o hecho, lo que presupone construir una imagen de epidemia devastadora y mortífera. O sea, se construye una imagen estigmatizante.

Como aspectos positivos, la oleada 2010 muestra que tan sólo se relaciona explícitamente con muerte en el 13, 82 de las piezas -cifra aún menor cuando el argumento central es el VIH/sida, el $12,38 \%$, frente al $28,36 \%$ de las piezas de 2006 y el $18,16 \%$ en 2008. Con otras palabras, se puede hablar de VIH/sida sin tener que hablar de muerte. Ahora bien, es una disminución que se centra geográficamente en España, Europa o Estados Unidos, pero el vínculo VIH/sida- muerte se mantiene cuando la pieza se ubica en África (se percibe, de esta manera, el acceso o no en cada región a los tratamientos antirretrovirales).

\footnotetext{
${ }^{9}$ A esta misma conclusión también llega en el estudio de CALANDRIA (2006). Consideramos que la acumulación de información entorno a los acontecimientos se convierte en una sobreinformación negativa, tanto para las redacciones como para los destinatarios: el que se hable mucho durante momentos puntuales eximen o impiden a las redacciones a tratar el tema con una mayor continuidad y hace que el destinatario pierda interés sobre el tema.

${ }^{10}$ Que merece por si sólo una investigación; el VIH/sida fue usado en numerosas piezas como argumento para mostrarnos una Sudáfrica peligrosa no preparada para organizar un evento mundial. A la par, tratar tanto Sudáfrica hizo que se hablara menos del resto del continente africano.
} 
Ahora bien, ¿las piezas hablan del sida, del VIH o del VIH/sida? Cabe precisar que cuando se habla de sida se está hablando de VIH y sida, de sida o, simplemente, de VIH; mientras que cuando se habla de VIH se hace una diferencia trascendente y clarificadora entre VIH y sida; y si se habla de VIH y sida, en numerosos casos sólo se debería hablar de VIH. En definitiva, en muchas ocasiones se toma la parte por el todo, el sida por el $\mathrm{VIH} /$ sida. Esta sinécdoque se da en el 40,51\% de las piezas en 2006 , y en el $48,51 \%$ en 2008. Designar sida, hablar de sida cuando debe hacerse de VIH o de ambas cosas no sólo es un error lingüístico, es una manera de enfocar el tema, de comprenderlo, de tratarlo y de presentarlo. En 2010 la proporción disminuye al 36,53\% de las piezas (y que aumentan cuantiosamente las citaciones de VIH); con otras palabras, cada vez se hace una distinción mayor entre VIH y sida. Además, se ha hecho usual la expresión personas que viven con VIH en sustitución de seropositivo, portadores o de personas que sufren, padecen...sida.

Por otro lado, en las tres oleadas prevalece, en todos los diarios, un enfoque neutro en las piezas. El enfoque pesimista suele ir ligado a drama, tragedia, muerte, devastación, pobreza, exclusión y subdesarrollo. El enfoque optimista se liga, en muchos casos, a avance biomédico o actitud positiva de las personas con VIH.

\subsection{Géneros, registros linguísticos y fuentes}

El uso de macrogéneros, o sea el conjunto de géneros informativos afines, y registros linguísticos (conjunto de variables contextuales, sociolingüísticas y de otro tipo que condicionan el modo en que una lengua es usada en un contexto concreto) nos ofrecen datos muy significativos: en el macrogénero informativo se pasa de 276 piezas en 2006 a 253 en 2008 y a 205 en 2010; en el interpretativo, de 159 en 2006 a 160 en 2008 y 192 en 2010; y en el de opinión, de 34 en 2006 a 22 en 2008 y 30 en 2010. Por otro lado, en el registro lingüístico informativo se pasa de 362 piezas en 2006 a 391 en 2008 y 408 en 2010, y en el divulgativo, de 107 en 2006 a 44 en 2008 y 19 en 2010. Estos datos indican, por un lado, la poca especialización en salud de las redacciones y, por otro, el interés relativo de los periódicos analizados respecto al VIH/sida. Se informa, pero no se explica. El cómo, el por qué, la contextualización (incluso la curiosidad científica) se aplican en una proporción muy escasa. Se aprecia que a la par de que con el tiempo se habla menos del VIH/sida también se explica, se contextualiza menos ${ }^{11}$ bajo el doble supuesto de que todo está ya explicado y de que todo se da ya por sabido.

En cuanto a las fuentes, prevalecen las institucionales (creíbles, estables y que son capaces de generar agenda). Las agencias gubernamentales siguen siendo líderes (17,11\% Ministerio de Sanidad y Consumo y Agencias Autonómicas), expertos científicos $(13,55 \%)$, ONG $(12,48 \%)$, centros de investigación $(9,45 \%)$ y organizaciones internacionales $(6,06 \%)$. Sobresale el dato de que las ONG se han consolidado como fuentes de información, siendo las ONG del ámbito del VIH/sida las más usadas con

\footnotetext{
${ }^{11}$ Trevor Cullen, de la Universidad Edith Cowan (Australia), quien investiga desde hace 12 años la cobertura periodística sobre el sida, ha denunciado en numerosas ocasiones que los medios de comunicación suelen omitir los por qué y los cómo: http://www.trevorcullen.id.au/
} 
gran diferencia. En cambio, las personas afectadas -directa o indirectamente no se usan como fuente (sólo en un 3,39\% de las piezas). Su voz queda subsumida en la de las ONG y denota, en gran medida, el miedo al estigma social que tienen, con razón, las personas que viven con VIH. Ahora bien, esta proporción tan baja también tiene su vertiente positiva, dado que muchas veces sólo sirven como coartada para la redacción de piezas melodramáticas que, como asegura Asturias (1999), no son más la construcción de relatos sensacionalistas que lastiman a la humanidad.

Parecería, por otro lado, que las revistas científicas deberían usarse como fuentes con cierta profusión, pero no es así y en paralelo al marcado descenso del registro divulgativo se da el descenso del uso de las revistas científicas como fuentes de los relatos periodísticos. Si en 200852 piezas $(11,95 \%)$ tienen su origen confeso en estas revistas, en 2010 sólo se hace en 19 casos (el 4,45\% de las piezas).

\subsection{Prevención, biomedicina y errores linguísticos}

En las piezas se habla menos de prevención ${ }^{12}$ (se pasa de un 38,38\% en 2006 a un $28,05 \%$ en 2008 y a un $17,33 \%$ en 2010 ); quizás pueda deberse a que los periodistas consideren que es un tópico ya 'agotado' dado que los destinatarios contarían con la suficiente información. Sin embargo, las estadísticas parecen demostrar lo contrario ${ }^{13}$; o si se desea, basta con acudir a cualquier foro sobre VIH/sida y observar las preguntas y comentarios que se realizan.

Por contra, y resulta paradójico, se habla más de prácticas de riesgo: por ejemplo, en el ítem sexo inseguro se pasa de tratarse en el 21,23\% de las piezas en 2006 al 27, $12 \%$ en 2008. En 2010 el 27,86 \% de las piezas incluyen alguna mención a prácticas de riesgo. Esta cifra es superior a la de piezas que tratan de prevención, tal como ya ocurriera en la oleada anterior. El porcentaje aumenta cuando son piezas cuyo argumento central es el VIH/sida; se llega al 39,52\%. ¿A qué se debe? Sobre todo a focalizar numerosas informaciones en continentes como África y centrarse en temas como las violaciones, la prostitución o el patriarcado (cuanto más lejano geográficamente es el foco de la información hay menos probabilidades de que se hable de prevención) y, en menor medida, a que en las piezas se intente contrarrestar la relajación de la población sobre las medidas preventivas (tengamos en cuenta que según el Registro Nacional del Sida se observa un predominio de la transmisión sexual, suponiendo el 55,2\% de los nuevos casos de sida en 2008) ${ }^{14}$.

No creemos que hablar de prácticas de riesgo suponga automáticamente el que se haga de prevención. Por otro lado, pensamos que en relación a las prácticas sexuales, los escritos suelen ser en exceso pacatos, moralistas o alambicados, y se ignoran gran parte de ellas.

\footnotetext{
${ }^{12}$ Asturias (1999) nos dice de que "un periodismo consciente no olvida su función orientadora hacia las transformaciones de fondo requeridas para cambiar el rumbo de esta epidemia” y hace hincapié en la necesidad de tratar una y otra vez las medidas preventivas. ${ }^{13}$ Véanse, como ejemplo, los datos del Registro Nacional del Sida (oleada hasta el 30 de junio de 2009): http://www.msps. es/ciudadanos/enfLesiones/enfTransmisibles/sida/vigilancia/SPNSInforme30Jun2009.pdff

${ }^{14}$ Véanse, como ejemplo, los resultados de la Encuesta Nacional de Salud Sexual 2009 http://www.msc.es/organizacion/ sns/planCalidadSNS/docs/v5_presentacion_ResultadosENSS_16dic09.pdf
} 
En cuanto a la práctica de riesgo de compartir jeringuillas (ítem drogas por vía parenteral) se aprecia como se trata menos en las piezas analizadas: 39 en 2006, 33 en 2008 y 29 en 2010. Si bien es cierta la disminución de esta práctica de riesgo, también lo es que debemos tener presentes otros considerandos. Tal como manifiesta Garabato González (2003:152), “los drogodependientes, al ser un grupo marginal no tienen el poder que si tienen otros sectores sociales para aparecer en la prensa". Recordemos que el grupo de usuarios o ex-usuarios de drogas por vía parenteral (UDVP) es el más numeroso en cuanto a los casos de sida diagnosticados en 2008 en España: 37,6\% entre los hombres y 23,4\% entre las mujeres, aunque se mantiene la tendencia descendente iniciada años atrás, en tanto que se observa una disminución en el número de casos diagnosticados del $28 \%$ respecto a 2007. Debemos hacer notar que hablamos de casos diagnosticados de sida y no de número de infecciones nuevas; en España no existe un registro nacional de infecciones.

También hemos de consignar que en las tres oleadas dos de cada tres piezas carecen de alguna referencia biomédica y sólo en un diario, El Mundo, una de cada dos noticias incorpora una o varias de las variables de información biomédica. Estos datos contrastan con el tópico de que las piezas sobre el VIH/sida son excesivamente biomédicas y que este tópico predominante haría que no se enfocara la pandemia desde otros puntos de vista. La realidad nos muestra de que se trata únicamente de una percepción y que habrá que buscar en otros factores el que no se trate el VIH/sida desde enfoques diferentes a los habituales.

A su vez, destaca un descenso en el número de usos incorrectos del lenguaje: se dieron en 111 de las 427 piezas analizadas (un 25,99\% del número total de piezas) y sólo tres variables se repiten en más de 10 ocasiones, por este orden: virus del VIH, contagio e infectado de sida. Consideramos que los errores se deben, una vez más y groso modo, a no distinguir o no saber distinguir entre VIH y sida, por un lado, y por otro, al uso de la sinécdoque (sida como todo). Eso sí, en dos últimas oleadas tan sólo en una ocasión se habla de grupo de riesgo; en la actualidad se escribe sobre los grupos o personas más vulnerables.

Ahora bien, el número de piezas con errores desciende de forma considerable cuando nos fijamos en las que tienen como argumento central el VIH/sida; se pasa a $11,47 \%$. Tenemos que resaltar esos 14 puntos a la baja en este tipo de piezas, pues nos vienen a decir que existe más cuidado y acierto en la redacción cuando el periodista trata como argumento central el VIH/sida (suele coincidir, en muchos casos, con los relatos hechos por los periodistas especializados en salud).

\section{4. ¿De qué, de quiénes se habla?}

Enunciaremos de manera sucinta algunas de las conclusiones a las que podemos llegar en esta tercera oleada. En primer lugar, el sujeto informativo sería, cada vez más, el $\mathrm{VIH} /$ sida y no la persona con VIH/sida. En segundo lugar, el asunto del que más informaron los medios analizados fue la prueba rápida de detección de anticuerpos del VIH. En tercer lugar, cada vez se relaciona más migración y VIH/sida.

Otro de los temas con mayor presencia en los diarios analizados, y sobre todo en comparación con las anteriores investigaciones, fue el de hombres que tienen sexo con otros hombres (HSH), que dobla su presencia en las piezas respecto a 2008 y aparece 
generalmente ligado a cierta relajación en la prevención por parte de los homosexuales - sobre todo de los más jóvenes. Este asunto está ocasionando reflexiones y controversias: cómo informar de una realidad objetiva sin promover, aunque sea de manera no premeditada, la estigmatización del colectivo homosexual.

A la par, se sigue ligando VIH/sida a pobreza, marginación y desigualdad. Resulta muy preocupante que la supuesta cronicidad de la pandemia (allá donde se tiene acceso a los tratamientos) está suponiendo no sólo esa relajación en las prácticas de riesgo; también se puede apreciar una banalización, una frivolización (en muchos casos como figura retórica) del VIH/sida en los relatos periodísticos. Y aumenta considerablemente el número de piezas en la que se da cuenta de la solidaridad de los famosos (cabría preguntarse cuál es el argumento central de estas piezas, ¿el famoso o el VIH/sida?).

Sólo en 17 piezas se recoge de manera explícita una denuncia por discriminación. La cifra es inferior a la de la oleada 2008, pues se ha pasado del 6,90\% al actual 3,98\%. Escribíamos en 2008 que los resultados resultarían decepcionantes para ONG y activistas. Nos parece muy preocupante esa reducción a la mitad dado que muestra, de alguna manera, que la estigmatización social permanece invisible.

Quienes más denuncian las discriminaciones son las organizaciones o individuos del ámbito VIH/sida y organizaciones o individuos que defienden los derechos de los homosexuales, y lo hacen, sobre todo a instituciones gubernamentales. Sobresalen las discriminaciones médicas y laborales. Los medios de comunicación no son denunciados.

En la oleada 2010 continúa la concentración geográfica en cuanto a la ubicación de las informaciones. Y al igual que en la oleada de 2.008, el orden, decreciente, es España (que aumenta ostensiblemente), Mundo, Occidente y África; el resto de las ubicaciones geográficas, a excepción de Asia y Latinoamérica (con un ligero repunte) son anecdóticas. Como escribíamos en 2008, hemos de tener en cuenta que la variable Mundo en gran medida es Occidente, por lo que se puede afirmar que fuera de Occidente (e incluimos la variable España) sólo tiene cierta entidad África, que en la oleada de 2010 es sinónimo de pandemia-tragedia y de fútbol.

Debemos añadir que la mujer tiene más presencia cuando el argumento central es el $\mathrm{VIH} /$ sida $(23,41 \%$ en 2008 y 30,47\% en 2010). Hay más piezas que tratan a la mujer como eje central de la información (se ha pasado de un 5.98\% al actual 8,2\%), aunque en relación al conjunto de piezas sigue siendo una proporción baja. El rol primordial de la mujer en las noticias es el de Actora (del hecho noticioso), seguido de los de Experta y de Testimonio. De estos datos cabe valorar como el más positivo el que el porcentaje de Experta sea superior al de Testimonio, lo que cualifica a la mujer. Sin embargo, la investigación constata que no se escribe sobre feminización del VIH/sida, las voces y puntos de vista de las mujeres son menores que las de los hombres, la (des)igualdad de género no es considerada como de interés noticioso y el género de la autoría no conlleva una mayor o menor presencia de la mujer.

Y por último, ¿qué busca la gente cuando se informa de VIH en Internet? Llama la atención que, según Google Insights for Search, el término de búsqueda en España que más se repite con la entrada "sida" es sintoma, un dato que lleva a la reflexión sobre el conocimiento sobre el VIH/sida y el éxito de las medidas y campañas de prevención. 


\section{Acciones emprendidas por el Observatorio de Derechos Humanos y VIH/sida de Red2002}

En el V Foro Latinoamericano y del Caribe en VIH/SIDA e ITS Perú ${ }^{15}$ se llegó una conclusión unánime: los medios de comunicación cumplen un papel importante como formadores de opinión pública sobre el tema del sida. A su vez, desde la Iniciativa de Medios Latinoamericanos sobre el Sida (IMLAS) ${ }^{16}$, se hace hincapié en la necesidad de que las entidades que trabajan en prevención del VIH y en el reconocimiento de los derechos de las personas que viven con el virus, formen alianzas con medios de comunicación para combatir la epidemia. Estas afirmaciones no son nuevas; cabe recordar, por ejemplo, las palabras de Garabato González, S (2003: 152): "Por otro lado habría que realizar jornadas de prevención del VIH/sida para que aparezcan noticias que traten ese tema, pues se ha comprobado que es cuando la prensa se muestra interesada y le presta mayor atención. Así como identificar a los periodistas concretos que escriben sobre VIH/sida y sensibilizarlos en la importancia de lo que se publica en los diarios sobre prevención del $V I H / s i d a$, en particular y sobre el sida en general e implicarles como agentes de salud. Sería oportuno tener más técnicos de salud especializados en medios de comunicación".

Como hemos apuntado en la Introducción, Red2002 se plantea en un principio la redacción de una Guía de buenas prácticas dirigida a los periodistas, pero tras la presentación de los resultados de la primera tanda de la investigación (Madrid, noviembre de 2006) optan por no realizarla; y esto se debe a dos razones: por un lado, Cesida acababa de publicar una guía de características semejantes: Guía de estilo: Salud y medios de comunicación. VIH/SIDA ${ }^{17}$ y, por otro, el resultado de la presentación de los resultados ante un grupo de periodistas, muchos de ellos redactores de salud de los medios analizados.

Detengámonos en esta reunión, no exenta de cierta tensión: los resultados de la investigación sorprenden y preocupan a los periodistas asistentes y sirven como acicate para un intercambio de ideas de cómo se trataba y cómo debería tratarse el VIH/sida en los medios. De lo que allí se expuso merece destacar qué reclamaron los periodistas a las ONG para favorecer un cambio en el tratamiento de las informaciones: que las ONG comprendieran las rutinas de producción de los medios, que fueran capaces de convertirse en fuentes estables, que les proporcionaran datos y no sólo opiniones, que les facilitaran testimonios ${ }^{18}$, que generaran noticias y que redactaran notas y comunicados de acorde con la narrativa periodística.

La presentación de la investigación deriva en una conclusión: era necesaria la cooperación entre periodistas y ONG. Así, meses más tarde (22 y 23 de marzo de 2007), se realiza en Madrid un taller-encuentro entre periodistas especializados en salud y ONG

\footnotetext{
${ }^{15}$ www.forovih2009.minsa.gob.pe/

${ }^{16}$ www.imlasida.org/

${ }^{17}$ http://www.pfizer.es/docs/pdf/sala_prensa/guia-estilo-medios-comunicacion-sobre-sida.pdf

${ }^{18}$ Para poder realizar ciertas piezas o ciertos tratamientos informativos, los periodistas se encuentran con la dificultad de carecer de testimonios. Éstos, por su parte, son reacios a aparecer en los medios dado que, por un lado, pierden el anonimato (miedo a la estigmatización social) y, por otro, desconfían de cómo les presentan, del uso que hacen de sus vivencias y palabras (desconfianza basada en la evidencia). La dificultad de encontrar testimonios es aún mayor cuando se pretenden imágenes.
} 
("Estrategias de comunicación para organizaciones civiles”) con la finalidad de institucionalizar la relación entre ambas instancias.

Esa necesidad de cooperación entre periodistas y ONG se dotó de un instrumento, el Centro de Recursos Mediáticos en VIH $^{19}$, que se presentó el 13 de marzo de 2008 en Madrid con el objetivo de ser un puente de encuentro entre los medios de comunicación y las ONG que trabajan en el área VIH/sida en España. De esta forma, y tras un proceso de diálogo entre periodistas y ONG, el primer estudio del OCS sobre el tratamiento del $\mathrm{VIH} /$ sida de la prensa española, sus conclusiones, dan pie a la creación de Mediosysida.

¿Qué es Mediosysida.org? es un sitio online que ofrece a los periodistas fuentes de información, testimonios y documentación para elaborar sus textos informativos y, al mismo tiempo, es una herramienta a disposición de las ONG para que éstas difundan sus mensajes, actividades y reivindicaciones y puedan entrar en contacto con periodistas y medios. Los objetivos del sitio son, por un lado, el permitir el acceso de manera rápida a las fuentes de información, mejorar la calidad de la información sobre el VIH/ sida y contribuir a erradicar el lenguaje estigmatizador difundido desde los medios y, por otro, contribuir a una mayor difusión de los mensajes de las ONG en los medios de comunicación para cambiar, así, la imagen social del VIH y con ello la discriminación que experimentan las personas que viven con él.

En esta página web se incluye una guía, "Manual de medios para asociaciones civiles: Estrategias de comunicación en VIH/SIDA", cuya finalidad es la de ofrecer un material de autoaprendizaje y referencia que pueda ser utilizado por personas que trabajan en el ámbito de las asociaciones civiles que no tienen formación como periodistas y, sin embargo, son las portavoces y comunicadoras de sus organizaciones. A la par, Mediosysida organiza talleres de formación para las ONG con el objetivo de brindar herramientas para saber cómo colaborar con los medios de comunicación y participa en eventos en los que a usa las conclusiones de los estudios para propiciar una reflexión colaborativa de cómo introducir en la agenda de los medios información novedosa y de calidad sobre el VIH/sida.

A partir de los datos que hemos ido ofreciendo, nos parece importante intentar resumir las líneas estratégicas emprendidas por el ODH de Red2002:

a) Sin renunciar a los medios propios, intentar influir sobre la agenda de los medios y el tratamiento de la información sobre VIH/sida. Para ello se han basado en:

- Utilizar las investigaciones del OCS como argumento fundamental para propiciar el cambio de actitud y de rutinas de los periodistas que redactan piezas sobre el VIH/sida.

- Asumir la necesidad de ofrecer información de acorde a unas rutinas de producción y a las características textuales de las piezas periodísticas.

- Institucionalizarse como fuente

- Realizar un trabajo cooperativo con los medios de comunicación

- Crear lazos de confianza con los periodistas 
b) Formar a los portavoces y comunicadores de las ONG para que entiendan las rutinas de producción periodística y asuman la elaboración de textos de acorde a unas características textuales

\section{Conclusiones}

En su clásico Le sida, Jerome Strazzula (1993) escribe que “la epidemia representa algo más que una enfermedad, el sida es un fenómeno mediático: los medios "revelaron» al mundo la existencia de esta patología y también los medios han sido decisivos en la propia historia de la enfermedad". Opinión que comparte, entre muchos otros autores, JM Catalán (2003), quien además nos hace ver que el VIH/sida es una de las claves para el desarrollo del periodismo especializado en salud en España. Ahora bien, Baker (1998) nos recuerda que el VIH/sida no es fenómeno mediático hasta que los ciudadanos, la Administración y los medios de comunicación no hicieron del sida un problema social y este no trascendió a toda la sociedad.

Este texto pretende mostrar como a partir de una investigación, Red2002 ha emprendido una serie de intervenciones para que cambie la imagen del VIH/sida que ofrecen los medios españoles. Nos parece relevante destacar como esas intervenciones se basan en la cooperación:

- Por un lado, entre investigadores y Red2002, dado que desde un principio se planteó como investigación aplicada y en su concepción y diseño participan al unísono el OCS y el ODH de Red2002. Más allá de la obtención de información se pretendía que la misma sirviera de base para las acciones que debía emprender la propia Red2002. Esta cooperación entre organizaciones ha trascendido a la propia investigación y ha dado pie a la colaboración en la búsqueda y puesta en marcha de instrumentos y estrategias que tuvieran como finalidad una imagen del VIH/sida no estigmatizante.

- Por otro, entre Red2002 y los periodistas especializados en salud, buscando actuaciones que beneficiaran a las dos partes y que permitieran influir en la agenda y en el tratamiento de la información sin que los periodistas lo vieran como una intromisión en su trabajo o tuvieran una percepción de instrumentación. Para nosotros, como investigadores, esta cooperación nos ha de suscitar una reflexión en un tema abierto y polémico en la comunicación para la salud: el rol de los periodistas especializados en salud, hasta qué punto han de ser o no agentes de salud ${ }^{20}$ y cuáles han de ser los principios ${ }^{21}$ sobre las que construir su profesionalismo.

\footnotetext{
${ }^{20}$ Asturias (1999): "Más que el mero traslado de información, el periodismo relacionado con el Sida tiene que ver con motivar cambios en actitudes y prácticas muy arraigadas que impiden la contención de la epidemia”. A su vez, en Hacia la Formación de Periodistas en Salud. Propuesta de Bases Curriculares para América Latina, VV.AA. (2002:14) podemos leer: "consideramos que el Periodista en Salud es el profesional que identifica, en un contexto determinado, temas y problemas de salud, pero con el firme propósito de promover prácticas sociales que favorezcan la calidad de vida y por ende, que se atiendan de manera integral los factores de incidencia".

${ }^{21}$ VV.AA.: (2004): Consideracions ètiques entorn de la informació sanitària, Barcelona, Comité de Bioética de CatalunyaGeneralitat de Catalunya, Departament de Salut.
} 
Consideramos prematuro el que se pueda realizar una evaluación de las intervenciones de Red2002; ha de transcurrir más tiempo para poder analizarlas con tino. Futuras investigaciones sobre el tratamiento informativo del VIH/sida y una específica encaminada a evaluar los resultados de las acciones emprendidas por Red2002 nos servirán para ver el alcance del trabajo cooperativo entre ONG y periodistas especializados en salud.

\section{References}

Ampuero, J. (2006) Estudio de Medios: Cómo los medios de comunicación informan sobre el VIH y cómo lo pueden hacer mejor, Lima: Calandria.

Amstrong, S. (2006). Transmitir mensajes: los medios de comunicación y la respuesta al SIDA, Ginebra: ONUSIDA. http://data.unaids.org/pub/Report/2006/jc1094-massmediasa_es.pdf

Asturias L. (1999). "El papel de los medios de comunicación en la problemática del VIH/SIDA en Guatemala", SIDA Abora, 2: 24-26.

Barker, A. J. (1998). “The portrayal of AIDS in the Media: An analysis of articles in the New York Times”, en: Feldman, D. A.; Johnson, Th. M. (eds.): The Social Dimensions of AIDS, Nueva York: Praeger.

Belenguer Jané, M. (2003). "Información y divulgación científica: dos conceptos paralelos y complementarios en el periodismo científico", Estudios sobre el Mensaje Periodístico, 9: 43-53.

Bizzo, MLG (2002). "Difusão científica, comunicação e saúde", Cad. Saúde Pública, 18(1): 307-314.

Brito Lemus, A. (2007). Sida, estigma y discriminación. Guía práctica de manejos de medios, México: Letra S, Salud, Sexualidad, Sida; suplemento de La Jornada.

Casabona, J. (2009). "El sida, ¿una epidemia secuestrada?”, El Periódico de Catalunya, http://www.elperiodico.com/default.asp?idpublicacio_PK=46\&idioma=CAS\&idnoticia_PK=666650\&idseccio_PK=1006

Catalán, J. M. (2003). iInfórmate en salud!: los medios de comunicación y la información sanitaria, Madrid: Eneida.

Comité de Bioética de Catalunya (2004). Consideracions ètiques entorn de la informació sanitària, Barcelona: Comité de Bioética de Catalunya-Generalitat de Catalunya, Departament de Salut.

Collins, H. (2002). "Respuesta de los medios de comunicación internacionales hacia el HIV durante los últimos 20 años”. QUARK, 24. http://www.prbb.org/quark/24/Default.htm

Garabato González, S (2003). "La prevención del VIH/sida en los medios de comunicación social escritos: análisis cuantitativo de una muestra de diarios”, Trabajo social y salud, 45: 139-154.

Knaeber, H. (coord.) (2008). VIH/SIDA: Guía para la cobertura periodística, América Latina, Montevideo: UNESCO. http://unesdoc.unesco.org/images/0017/001780/ 178043s.pdf

Kuscinsky, B. (2002). "Jornalismo e saúde na era neoliberal”, Saude e Sociedade, 11(1): 95-103.

Mercado Martinez, F. J.; Robles Silva, L.; Moreno Leal, N.; Franco Almazán, C. (2001). "Inconsistent journalism: The coverage of chronic diseases in the Mexican press", Journal of Health Communication, 6 (3): 235-247.

Mosquera, J.; Mateus, J. C. (2003). “Conocimientos, actitudes y prácticas sobre métodos de planificación familiar, VIH-SIDA y el uso de los medios de comunicación en jóvenes”, Colombia Médica, 34, (4): 206$-212$.

Nanda, S.; Pramanik, A. (2009). "HIV/AIDS in India: stigmatization as a process of communication and social relationship", Cuadernos de Información, 25: 105-111.

Santos, A. (2009). "As Mulheres no discurso jornalístico sobre o VIH/Sida: um estudo preliminar sobre a reprodução de estereótipos 24". Lisboa, Actas $6{ }^{\circ}$ Congresso SOPCOM, 4580-4595.

Strazulla, Jérôme (1993). Le Sida, París: La documentation Française.

Tufte, T. (2006). "Stigma: the key challenge for HIV/AIDS Communications", en Glocal Times, 4, http:// www.glocaltimes.k3.mah.se/viewarticle.aspx? articleID $=64 \&$ issueID $=6$

VV.AA. (2008). Guía para la Cobertura del VIH/SIDA, Buenos Aires: Fundación Henry J. Kaiser Family y Fundación Huésped.

VV.AA. (2002). Hacia la Formación de Periodistas en Salud. Propuesta de Bases Curriculares para América Latina, Washington-Lima: OPS/OMS. 